\title{
Neurotrophic (Neural Stimulating) and Neuromediator Effects of Hirudo medicinalis. Pathogenetic Mechanism of Treatment of Diseases of the Nervous System of the Human
}

\section{Krashenyuk AI*}

Academy of Hirudotherapy, St. Petersburg

*Corresponding Author: Krashenyuk AI, Academy of Hirudotherapy, St. Petersburg.

DOI: $10.31080 / A S M S .2020 .04 .0552$
Received: January 20, 2020

Published: February 06, 2020

(C) All rights are reserved by Krashenyuk AI.

\begin{abstract} diseases of the human nervous system.

Keywords: Neurotrophic; Neuromediator; Hirudo medicinalis
\end{abstract}

This article is devoted to the discovery of new factors related to the biology of the medical leech and its application in various

\section{Introduction}

In 1994 The $5^{\text {th }}$ Federal TV channel of Russia showed a film entitled "Treatment of cerebral palsy - cerebral palsy." Readers of the magazine can still watch this film with the name "Cerebral Palsy can treat only in Russia" on our website (acadimia-hihudo.ru). The clinical results that we obtained in the treatment of cerebral palsy, myopathy [1-3], and the consequences of a stroke stimulated a scientific search for the cause and explanation of these phenomenal results. And in 1996 we patented the discovery of the neurotrophic (neuritic-stimulating) effect of Hirudo medicinalis [4].

Investigating further the effects of medical leeches, we also found that leeches are capable, like large hydrobionts (dolphins, killer whales, and whales), of generating an acoustic signal in the ultrasonic range of $25-250 \mathrm{kHz}$ (and most likely electromagnetic signals are acousto-electromagnetic signals!). This part of the research was carried out at the Physicotechnical Institute named after Academician F.A. Ioffe of the Russian Academy of Sciences, in the acoustics laboratory [5].

\section{Materials and Methods}

To detect neurotrophic (neuritic-stimulating) effects, the model of Nobel laureate Levi Montalcini was used - exposure of the gan- glia of 10 - 11-day-old chicken embryos with the addition of aqueous extracts of various leech body fragments to the culture medium. Before this, the bodies of leeches were frozen and then lyophilized [4]. All tubes had encrypted codes indicating the number of water extract of a specific part of the body of leeches.

The details of the detection of acoustic radiation (emission) of a medical leech are described in detail in our pioneering work [5].

The neurotransmitter effect of leeches was studied using the electrodynamic scanning method (superposition scanning method) developed by Ph.D. Yu.F. Kamynin [6].

\section{Results}

Figure 1 shows the results of a study of the neurotrophic (neuritic-stimulating) effect of a medical leech. When decrypting test tubes with aqueous extracts of fragments of the body of medical leeches, we invariably detected the presence of neurotrophic (neuritic-stimulating) effect only in fragments of the head part of leeches. It is in the head of leeches at the level of 3 - 9 somites and there are glandular salivary cells responsible for the synthesis and secretion of leech secretion, which leech injects into the body of the "host" - a person or an animal [7]. 


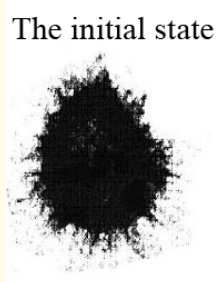

Organotypic culture of the spinal ganglia of the chicken embryo

Figure 1: Stimulation of nerve cells (neurons), observed using phase contrast microscopy of 10-11-day-old ganglion hicken embryo. Initial state and after leech impacts marked increase neurites - processes of the membrane of neurons. A detailed description of the discovery is given in [4].

In 1999 - 2001 at the Laboratory of Moscow State University, our discovery of the neurotrophic (neuritic-stimulating) effect of a medical leech was confirmed and it was shown that this effect is associated with the activity of at least three leech secretion peptides: destabilase-M, bdellin $\mathrm{B}$, and bdelastazine.

These and other individual peptides were in the collection of the laboratory of Moscow State University and were used in published experiments [8].

We present table 1 , which sets out comparative data on the neuritic stimulating activity of some already known drugs and proteins.

\begin{tabular}{|l|c|c|}
\hline $\begin{array}{l}\text { Biologically active } \\
\text { compounds }\end{array}$ & $\begin{array}{c}\text { Effective } \\
\text { concentra- } \\
\text { tion, ng / ml }\end{array}$ & Literary source \\
\hline Protein Kanase C & 10,0 & EdgarD.,1978 \\
\hline $\begin{array}{l}\text { Brain derived } \\
\text { neurotrophic factor }\end{array}$ & 0,04 & BardeY., et al.1980 \\
\hline Nerve growth factor & 20,0 & Levi-MontalciniR.,1982 \\
\hline $\begin{array}{l}\text { Ciliary Neurotrophic } \\
\text { Factor }\end{array}$ & 10,0 & $\begin{array}{c}\text { ManthorpheM., } \\
\text { et al.1982 }\end{array}$ \\
\hline Monosialgangliozidı & 200,0 & FacciL.,et al.1984 \\
\hline $\begin{array}{l}\text { Brain Neuritic } \\
\text { Stimulating Protein }\end{array}$ & 4,0 & $\begin{array}{c}\text { Goncharova VP., } \\
\text { et al. } 1985\end{array}$ \\
\hline $\begin{array}{l}\text { Fibroblast growth } \\
\text { factor }\end{array}$ & 100,0 & $\begin{array}{c}\text { Gospodarowicz D., } \\
\text { et al.1989 }\end{array}$ \\
\hline Cortexin & 100,0 & $\begin{array}{c}\text { Havinson V Kh., } \\
\text { et al. } 1997\end{array}$ \\
\hline Epitalamin & 200,0 & $\begin{array}{r}\text { Havinson V Kh., } \\
\text { et al. 1997 }\end{array}$ \\
\hline Destabilase-M & 0.01 and 0.05 & Chalisova N.I., et al. 1999 \\
\hline
\end{tabular}

Table 1
As follows from the table, destabilase-M leeches is 10,000 times more active than the popular drug cortexin, widely used in diseases of the nervous system of adults and children [9].

In our opinion, it is these peptides (and perhaps there are more?) that determines the therapeutic effect in diseases of the nervous system:

with cerebral palsy, post-stroke conditions, multiple sclerosis, Parkinson's disease, migraine, neurocirculatory dystonia, Alzheimer's disease, autism, neuritis of any origin, alalia, dysarthria, consequences of traumatic brain injury, memory loss, speech loss after a stroke and other diseases of the nervous system.

- 1 minutes: We observe the presence of dopamine on the periphery of the leech body and presence of histamine inside the body of a leech.

- 3 minutes: Brain: the appearance of the fields of Histamine, Serotonin, Dopamine, Gamma - Aminobutyric Acid (GABA). Leech: the appearance of Serotonin.

- 6 minutes Brain: Acetylcholine field appearance, Enkephalins / Endorphins, Noradrenaline.

- 9 minutes Brain: increased areas of neurotransmitter activity Norepinephrine.

- 12 minutes Brain: appearance of the field of cholecystokinin, substance P (peptide P), Taurine, Glutamine.

Comparative evaluation of the neuritic stimulating effect of some biologically active compounds [Baskova I.P., G.S. Isahanyan. Hirudotherapy. Science and practice, M. 2004, p.133].

- 15 minute Brain: the emergence of new separate zones of secretion, isolated from the primary zone, in the frontal, occipital, postorbital, and in the area of the cerebellum.

The phenomenon of polymorphic resonance [10]!

- 18 minutes Brain: an increase in the area of individual secretion zones.

- 21 minutes Brain: the beginning of a decrease in neurotransmitter fields. Leech: an increase in the concentration of neurotransmitters in the body of leeches.

- 24 minutes A sharp decrease in the fields of Enkephalins / Endorphins, transformation of isolated fields in Histamine Serotonin "fields.

- 5 minutes After leaving the leech from the lower ear fossa. Brain: a sharp decrease in the area of neurotransmitter activity.

- 15 minutes After leaving the leech from the lower ear fossa. Brain: even greater reduction in area neurotransmitter activity. 


\section{Neurotransmitters assigned color values}

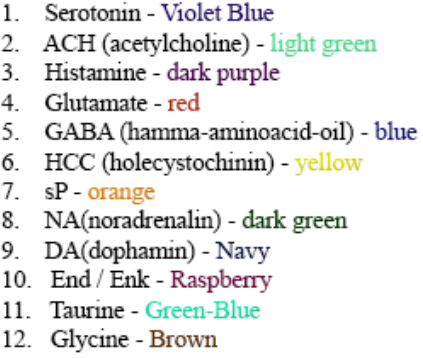

Figure

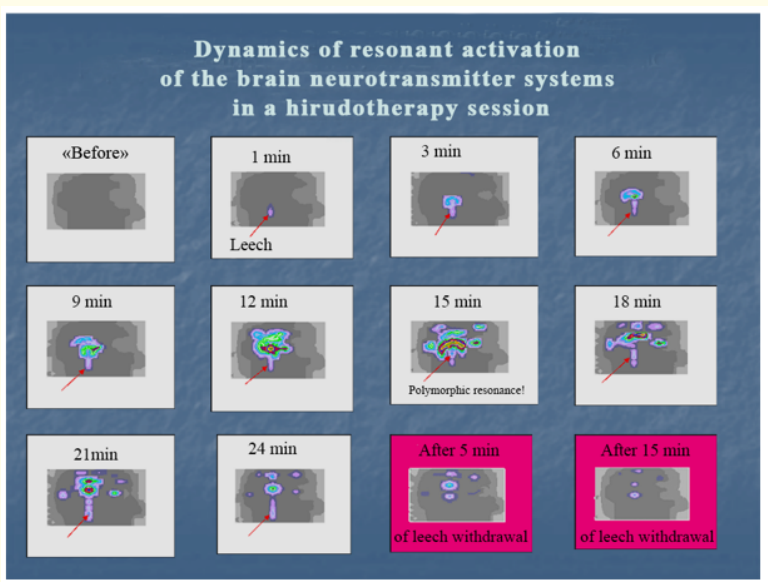

Figure 2: Dynamics of resonant activation of neurotransmitter systems brain in a hirudotherapy session (adult brain) [6]. Description of Figure 2: "To": the sensitivity of the device is as low as possible to observe the "Plus effect" of the leech. The leech was placed on the lower ear fossa and a brain scan was performed every 3 minutes.

Using the method of superpositional scanning of the brain, it was found that the "acute" effect of hydrotherapy on the brain has a two-phase character: during the first 15 minutes after at the end of the hydrotherapy session, an increase in the density of adenosine, serotonin and M-cholinergic receptors was noted, which was defined by us as a demobilization reaction.
In the subsequent 90 - 120 minutes, the density of serotonin receptors decreased and the activity of noradrenergic, dopaminergic and opiatergic structures increased - mobilization reaction.

These data on electromagnetic super positional scanning of the brain after a hydrotherapy session led to the conclusion that hydrotherapy produces a powerful multicomponent response to changes in the metabolism of the central nervous system, which has both an "acute" and a delayed character.

This response is probably related to the wave effect of the leech, since the hemodynamic parameters, taking into account the blood-brain barrier of the brain, have not yet had time to respond to the introduction of the components of the leech secretion into the blood. Moreover, the nature of changes in the neurotransmitter fields of the brain is associated with the regulation of all vegetative processes of the human body.

We investigated the dynamics of the secretion of neurotransmitters in the process of the hirudotherapy session itself. Analysis of these materials shows that already at the $3^{\text {rd }}$ minute of the leech action, the process of changing the concentration of neurotransmitters in the central nervous system (CNS) begins.

At the $9^{\text {th }}$ minute, we see that the pattern of stimulation of the secretion of neurotransmitters becomes disseminated, which is probably due to the mechanism of polymorphic resonance to the leech acoustic signal. This phenomenon manifests itself most vividly at the $15^{\text {th }}$ minute.

The phenomenon of polymorphic resonance was discovered by the creator of the anti-entropic direction in physics - Professor Smirnov A.P [10].

Hirudotherapy initiates the launch of a cascade of biochemical and biophysical reactions in the central nervous system. These reactions are associated with broad-spectrum secretion of neurotransmitters that regulate the tone of the autonomic nervous system (sympathetic and parasympathetic). And they carry out the process of self- regulation of all neuroendocrine processes.

The change in the activity of metabolic reactions completion is already the final stage of the "game" of the autonomic nervous of the body during the hydrotherapy session and after its system. 
However, the process of changing the neurotransmitter activity of the brain does not end there. We managed to track their change by examining the brain of a 4-year-old child, suffering from alalia, Figure 3.

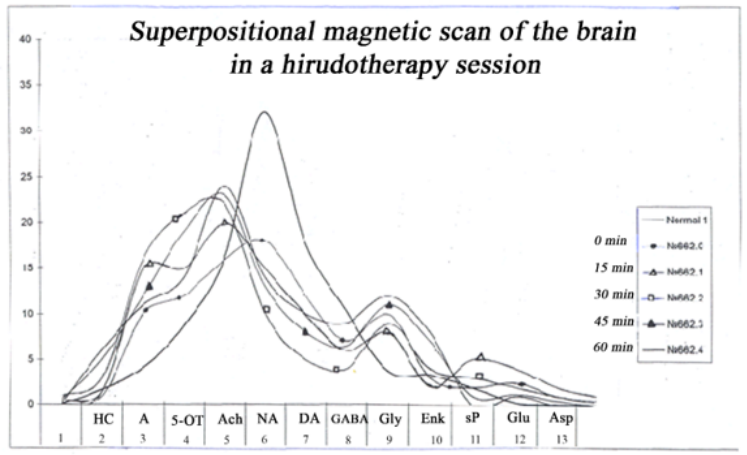

Child. 4 years 3 months. Diagnosis: Alalia. №662, 11.11.2002

Figure 3: The dynamics of changes in the concentration of neurotransmitters in the central nervous system after completion of a hirudotherapy session. The measurements were carried out with an interval of 15 minutes after the completion of the hirudotherapy session.

Legend: relative units are plotted on the vertical axis density of sources of electromagnetic radiation of the brain; along the horizontal axis - units of radiation density of various neuronal membrane receptors.

The abbreviated names of neurotransmitters are given:

HC - cholecystokinin; A - adrenaline; 5-OT - serotonin; Ach acetylcholine; NA - noradrenaline; DA- Dophamine Enkephalins / Endorphins; GABA - gamma-Gly - glycine; Glu - glutamate; aminooil sP - substance Pacid; Asp- asparagine.

This figure shows the dynamics of changes in the neurotransmitter activity of the brain of a child with measurement intervals of 15 minutes, for an hour. Two fundamental conclusions follow from Figure 3:

1. In the process of leech therapy and after its completion, for at least one hour, the content of serotonin in the brain increases. And this allows us to understand the work of genius empiricists in Russia (zemstvo doctors), who in the 19-th century put leeches to schizophrenics and epileptics in the phase of exacerbation - depression, in order to avoid suicides or acts of aggression.
2. Change in the dynamics of the concentration of Enkephalins / Endorphins and peptide $\mathrm{P}$ after one hour of observation (different phases of change). allows you to understand the mechanism of pain relief when using leeches for pain relief. In this we see the phenomenon of the manifestation of the phenomenon of the antinociceptive function of a medical leech.

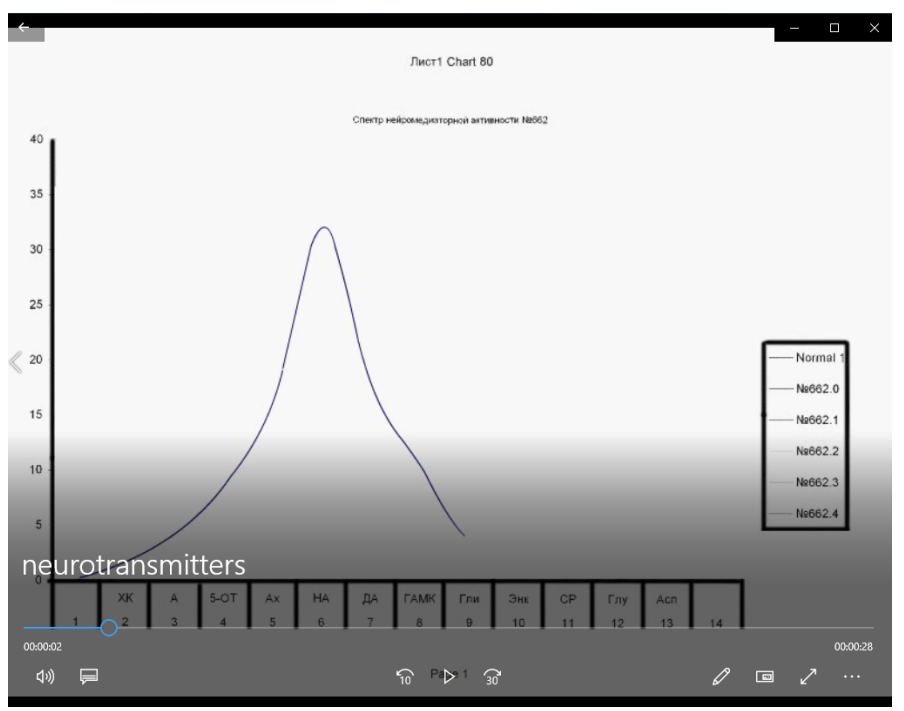

\section{Discussion}

The proposed article reflects whether only small part of my posts made in the past year, in Rome, in the 5th International Congress of Traditional and Alternative Medicine and the Congress for the Study of Acupuncture and Meridians (23 - 24 on April 2019 g) [11]. Title of the report: " The Renessans of Hirudotherapy in the Russia: The end of XX and the beginning XXI Century».

The work was warmly received by his colleagues from the 18 countries of the world. And it reflects the growing in of all the world's interest to the traditional methods of treatment. This is not a random process, as each country contributes to the "world treasury of traditional methods of treatment," his contribution.

Statistics from developed countries confirm this trend. In the United States and Canada, for example, on data epidemiological, side effects of drug therapy are located at 5-6 place in the explanation of causes of death after cardiovascular, oncological, Bronchopulmonary diseases and injury [12].

Allopathic medicine has already come to the point where the diagnosis of "Medicinal hepatitis" is no longer surprising! What does my personal experience says? According to the request of the 
editorial board of the magazine " Newsweek " in 2002. The journalist of this publication Eve Conant turned to me with a request to write an article for the journal "The Current State of Hirudotherapy in Russia».

The editors decided to devote this issue to the theme: "The Science of Alternative Medicine". This project seemed interesting to me, because the magazine is sold in many countries of the world and I wanted to tell readers about the study of leeches and their application in Russia. It was prepared by an article in formate A 44 pages.A rticle was written about opening neurotrophic factors, the wave emission and other unknown previously to science facts. It mentioned and treatment of many diseases of the nervous system of a person, including and disease Alzheimer's.

After the release considering the log from my article remained only one phrase. I bring it verbatim: " Americans use synthetic hirudins, a major component of leech secretions, for thrombosis of tissue repair ", says Dr. Albert Krashenyuk, President of St.- Petersburg 's Hirudology Association. "But the most effective - and cheapest - thing to do is to use a real leech."

In fact, my phrase was distorted. It sounded like this: "Never the synthetic components of a leech secret will replace the whole therapeutic power of a leech. I have in mind, and the wave effect of the leech (it was opened in 2001.), all new data allows to consider piyavkolechenie (hyrudotherapy) as the "High Technology ".

Later, I became aware that in the United States a slow death, dying, President of the USA Ronald Reagan and his wife Nancy from the disease of Alzheimer's.

Probably, the editors of the journal of " Newsweek " my message about the possibility of improving the condition of patients with the disease of Alzheimer's considered not opportune for the US and its former leader [13].

In conclusion I want to note that the ancient roots of the history of India and Russia, the similarity of gene pools of Hindus and Russian may reflects the interest of our peoples to the God's method - piyavkolechenie (hyrudotherapy). But this is another scientific study.

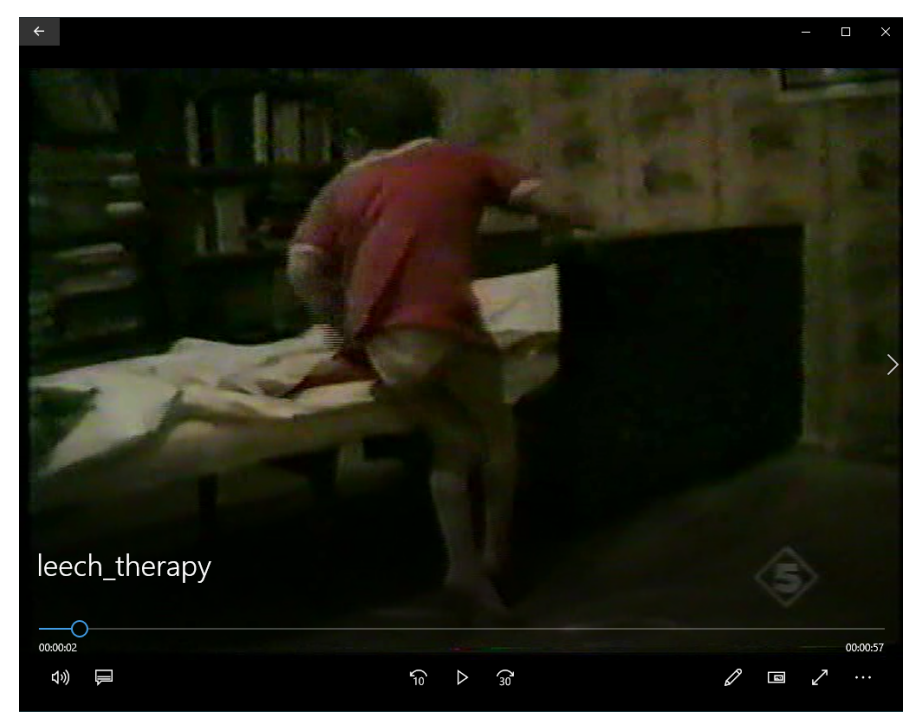

\section{Conclusions}

1. For the first time, the possibility of maximizing the achievement of a clinical positive effect in the treatment of cerebral palsy and other lesions of the central nervous system using the author's method of leech therapy has been shown.

2. It is proved that this effect is achieved by a pathogenetic pathway, due to the discovery of the neurotrophic effect [4], independently confirmed by other authors [8].

3. A mechanism has been discovered concentration of serotonin in for relieving depression during leech therapy by increasing the brain.

4. The mechanism has been discovered of the antinociceptive function of medical leeches.

Thanks. The author thanks the professors Smirnov A.P. and Slesarev V.I. for discussing the mechanism of the role of acousto-electromagnetic leech radiation in the generation of neurotransmitter fields in the human brain.

Thanks. The author thanks the dr. Kuryleva N.A. for brilliant design of article.

\section{Bibliography}

1. Krashenyuk AI and Krashenyuk SV. "Hirudotherapy as a rehabilitation method children with cerebral palsy". International Journal of Immunoreabilitation 4 (1997): 118. 
2. Krashenyuk AI and Krashenyuk SV. “Cerebral palsy. In book 6 Nikonov G.I. Medical leech. The basics of hirudotherapy". St. Petersburg. (1998): 154-155.

3. Krashenyuk AI and Krashenyuk SV. "Hirudotherapy in the treatment of myopathies. Successes of hirudology and hirudotherapy. Materials IV scientificpractical conference of the Association of Hirudologists of Russia". Under Ed. Krashenyuk A.I. St. Petersburg (1994): 18-20.

4. Krashenyuk AI., et al. "Modeling Method the effect of medical leeches on stimulation of nerve fiber growth in tissue culture". Patent for the Invention of the Russian 14 (1996).

5. Krashenyuk AI and Frolov DI. "Interpretation of nature energy-informational effect of hirudotherapy based acoustic phenomenon. Abstracts of the $\mathrm{V}$ International Congress of Bioelectrography "The science. Information. Consciousness". St. Petersburg (2001): 89-90.

6. Krashenyuk AI and Kamynin YuF. The neuroendocrine nature of the hirudotest Krashenyuk. "GIRUDO-2006", Materials IX of the scientific and practical conferences of the Association of Hirudologists of Russia Balakovo (2006): 33-36.

7. Baskova IP. "The scientific basis of hirudotherapy". Humoral link. Tula: Aquarius (2015c).

8. Baskova IP GS and Isahanyan. "Hirudotherapy". Science and Practice M (2004): 133.

9. Ryzhak GA., et al. "The use of cortexin for treatment of diseases of the central nervous system // Methodical recommendations - SPb.: ICF. The Tome (2001): 56.

10. Smirnov AP. "Polymorphic resonance. "Research Issues The universe". Materials of Congress - 2004 "Fundamental Studies of Natural Science and Technology". 29 (2004): 337-341.

11. Krashenyuk AI. "The Renessans of Hirudotherapy in the Russia: The end of XX and the beginning XXI Century". Journal of Regenerative Medicine 8 (2019): 42.

12. Postnov SE. "Border water in a living organism M LLC "ElfIPR" (2017): S72.

13. Conant Eve. "Blood-Sucking Bandages. "Newsweek" (2002): 51

\section{Assets from publication with us}

- Prompt Acknowledgement after receiving the article

- Thorough Double blinded peer review

- Rapid Publication

- Issue of Publication Certificate

- High visibility of your Published work

Website: https://www.actascientific.com/

Submit Article: https://www.actascientific.com/submission.php

Email us: editor@actascientific.com

Contact us: +919182824667 